\title{
X-Ray Fluorescence Spectrometry
}

National Cancer Institute

\section{Source}

National Cancer Institute. X-Ray Fluorescence Spectrometry. NCI Thesaurus. Code C85830.

A spectrometric method that determines the type and concentration of elements or chemicals in a sample, based upon the principle that each element emits fluorescent light of a particular wavelength when exposed to an X-ray. 